\title{
Absolute Value of $g$ at the National Bureau of Standards
}

\author{
D. R. Tate \\ Institute for Basic Standards, National Bureau of Standards, Washington, D.C.
}

(April 6. 1966)

\begin{abstract}
A determination of the absolute value of the acceleration due to gravity has been completed at the National Bureau of Standards near Gaithersburg. Maryland. The value, reduced to a gravity meter station on the floor of the site is $9.801018 \mathrm{~m} / \mathrm{s}^{2}$ with a standard deviation of $0.3 \times 10^{-5} \mathrm{~m} / \mathrm{s}^{2}$. The absolute value, which is $13.2 \times 10^{-5} \mathrm{~m} / \mathrm{s}^{2}$ (13.2 milligals) less than the corresponding Potsdam value, is in general agreement with other recent absolute determinations.
\end{abstract}

Key words: Absolute gravity, acceleration, free-fall, g. geodesy, gravity, Potsdam system.

The National Bureau of Standards has recently completed a determination of the acceleration due to gravity at its new facility near Gaithersburg, Md. The measurements were made in the Engineering Mechanics Building during the months of April, May, and June of 1965.

The determination was derived from observations of the increase in speed of a one-meter fused silica tube falling freely within a vacuum chamber which was itself falling with approximately the acceleration due to gravity. The measurements included data from four different fused silica tubes yielding a total of 36 sets of observations. Each set was normally composed of 16 independent free-fall observations. There were no statistically significant differences among the results for the four tubes, the observed variations being well within that expected on the basis of the standard deviation of $1.4 \times 10^{-5} \mathrm{~m} / \mathrm{s}^{2}$ found for individual sets of observations.

The determination was made in Room 129 of Building 202 at the National Bureau of Standards. The site is illustrated in figure 1 , taken from the 1965 report of D. A. Rice of the U.S. Coast and Geodetic Survey to Special Study Group No. 5 of the International Association of Geodesy, for their compilation of excenters $^{1}$ for World First Order Gravity Stations. The absolute determination was made $30 \mathrm{~cm}$ east and $26.3 \mathrm{~cm}$ above the point marked NBS-1. The absolute value was reduced to the reference point NBS-2 on the floor of the room by gravity meter connections made by the U.S. Coast and Geodetic Survey during October 1965. These connections are included in the report to Special Study Group No. $5 .^{2}$

The determination resulted in an absolute value of gravity for NBS-2 of:

$$
g=9.801018 \text { meters } / \text { second }^{2} .
$$

The standard deviation of this value based on statistical variation but not including systematic error was less than $0.3 \times 10^{-5} \mathrm{~m} / \mathrm{s}^{2}$

1 Excenters are gravity stations located in the vicinity of a primary station and connected to it by accurate gravity measurements. A connection to an excenter is equivalent in accuracy to a connection to the primary station.

${ }^{2}$ These data are available from the files of the U.S. Coast and Geodetic Survey.
The point NBS-2 has a value of $9.801150 \mathrm{~m} / \mathrm{s}^{2} \mathrm{ob}$ tained by gravity meter connections based on a Potsdam value of $9.80118 \mathrm{~m} / \mathrm{s}^{2}$ for the national gravity base in the Department of Commerce Building in Washington, D.C. The absolute value is therefore $13.2 \times 10^{-5} \mathrm{~m} / \mathrm{s}^{2}$ (13.2 milligals) less than the Potsdam value for NBS-2.

A complete description of the experimental procedure will be given in a forthcoming publication.

NORTH WALL OF BLDG.

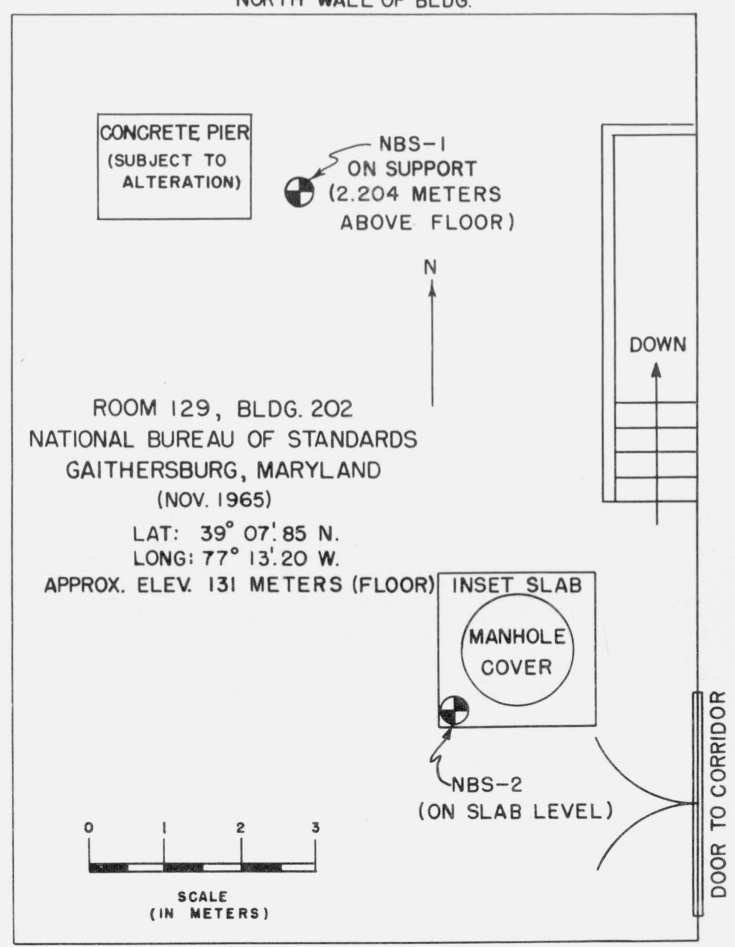

Figure 1. Gravity stations at the National Bureau of Standards. 